\title{
Welfare of a pair of Captive Tigers: a Hand-Reared Female and a Parent-
} Reared Male

Bertocchi M. ${ }^{1}$, Spiezio C. ${ }^{2}$, Di lanni F. ${ }^{1 *}$, Macchi E. ${ }^{3}$, Parmigiani E. ${ }^{1}$, Sandri C. ${ }^{2}$, Ponzio P. ${ }^{3}$, Quintavalla F. ${ }^{1}$

${ }^{1}$ Animal Health Department, Faculty of Veterinary Medicine, University of Parma, Via del Taglio 10, 43126 Parma, ITALY

${ }^{2}$ Research and Conservation Department, Parco Natura Viva - Garda Zoological Park, Località Figara 40, 37012 Bussolengo, VR, ITALY

${ }^{3}$ Veterinary Morphophysiology Department, Faculty of Veterinary Medicine, University of Turin, Via Leonardo da Vinci 44, 10095 Grugliasco, TO, ITALY

\section{ABSTRACT}

Animal welfare assessment has undergone considerable development. The management and rearing of big cats may lead these animals to express behavioral problems. This study was performed to assess the well-being of a non-breeding pair of Siberian tigers using ethological and physiological parameters. During the day, the animals were kept together in the outdoor exhibit, whereas overnight the tigers were individually housed. Twenty 45-min sessions were run for each subject. The Focal Animal Sampling method was used to record individual and social behaviors. In addition, fecal cortisol levels were monitored and determined by enzyme immunoassay. Single case analysis was run to analyze behavioral data and cortisol levels. Findings highlight that species-specific behaviors were performed by both animals. However, significant differences between the two tigers were observed in stress-related behaviors: the female showed stereotypic behavior, whereas the male did not. No significant differences in fecal cortisol levels were observed. Results suggest that the ethological parameters could be more sensitive than the physiological ones in detecting a stressful condition. Analyzing behavioral data together with physiological stress markers may allow for a more complete assessment of animal welfare.

\section{Indexing terms/Keywords}

Animal welfare; hand-rearing; tiger behavior; fecal cortisol; stereotypies.

\section{Academic Discipline And Sub-Disciplines}

Animal Welfare and Behavioural Medicine

\section{TYPE (METHODIAPPROACH)}

Preliminary study

\section{Council for Innovative Research}

Peer Review Research Publishing System

\section{Journal: JOURNAL OF ADVANCES IN AGRICULTURE}

Vol. 5, No. 1

www.cirjaa.com jaaeditor@gmail.com 


\section{INTRODUCTION}

Animal welfare assessment is becoming increasingly important for zoo animals and even more so for hand-reared individuals in whom this evaluation is essential (23). In the eighties, animal welfare was defined as "a state of complete health, both physical and mental, in which the animal is in harmony with its environment" and therefore, closely related to the ability of the individual to cope with the environment (8). This in turn is closely related to the concept of stress, initially defined by Selye as the "General Adaptation Syndrome" (50). More recently, stress has been considered as an environmental effect on an individual, which over-taxes its control systems and reduces its fitness or seems likely to do so $(10,11,12)$. In order to identify the most effective methods to assess animal welfare, it is essential to be able to recognize potential problematic situations, and when necessary, intervene in order to improve the welfare of the animal. The captive environment may lead to the expression of stereotypies in many animals, such as carnivores or primates $(29,33,53,57)$ In particular, species that typically occupy large home ranges in the wild are much more susceptible to welfare problems when housed in captivity (15). Indeed, felines are particularly prone to show abnormal behaviors, such as stereotypies, apathy or aggression (13). Tigers (Panthera tigris) are one of these species $(29,58)$. In particular, several elements may influence the behavior and therefore, the welfare of tigers housed in captivity. Bashaw et al. showed that these animals tend to display more pacing - i.e. walking repetitively back and forth in a particular pattern in its enclosure (22) - when kept in a small exhibit than when housed in larger areas (5). In addition, pathological changes in the behavior of captive tigers were observed in relation to feeding routines and methods of food display, for example the variation of the place for meal provision (4). The social environment is another fundamental element. Indeed, the influence of the social environment on the state of well-being of an individual depends on whether the animal itself has been parent-reared or hand-reared (23, 31). Nowadays in modern zoos, hand-rearing techniques are used only in cases of emergency, when there is no alternative (42). In particular, five categories of factors that may justify the decision to hand-rear may be recognized: environmental, social, and health factors, conditioning, and preventative medicine (42). It is well known that in the absence of early social contact, young primates may exhibit abnormal behaviors, such as abnormal reproductive behavior $(6,18$, $21,26,32)$, deficits in maternal behavior (45), self-sucking and stereotypic rocking $(30,37)$. Currently, some protocols have been proposed for hand-rearing techniques used with apes; however, very little information regarding these techniques in carnivores is available in literature (25). In particular, hand-rearing exotic carnivores may compromise the development of normal behavior (31). Indeed, proper socialization with conspecifics seems to be particularly important and could take up to three years $(43,44)$. Indeed, independently of whether socialization occurs at a later stage, these animals may develop behavioral problems, such as fear or aggression around conspecifics, lack of conspecific play, difficulty with reproduction and fixation on humans $(25,31)$. For this reason, in the case of hand-rearing exotic carnivores, it is crucial to provide young animals with enrichment and interactions with conspecifics $(25,31)$. Regarding tigers, parental rearing is preferred. In fact, when the cubs remain with their mothers, the benefits for the offspring are numerous, as among which nutritional, developmental and behavioral benefits $(19,25,31)$. However, sometimes hand-rearing is necessary. As for other species, this need may arise due to various factors, such as animals giving birth in unsuitable areas, excessive noise, or high levels of intervention in the first postpartum period $(20,25,43,44)$. A major challenge for hand-reared animals is the development of normal social behavior. The animal's behavior may indeed be profoundly affected by handrearing during the socialization period (31). Currently, the assessment of animal welfare is carried out using two methods: the ethological method or the physiological strategy. The first method consists in the observation of the qualitative and quantitative behavior of the animals, in particular assessing the expression of species-specific behaviors as well as any pathological behavioral responses (23). Whereas the physiological approach provides for the monitoring of the animal's biological function. Most studies on animal welfare choose to examine endocrine function because hormones mediate the animal's reaction to stressful situations. In particular, the measurement of cortisol and its metabolites has long been recognized as a reliable indicator of adrenal function and thus provides information on the animal's stress response (23). However, the most comprehensive strategy to assess animal welfare in a controlled environment seems to be the adoption of both methods, integrating the results. Indeed, relying upon only one approach has its limitations (23). There is a dearth of published literature regarding the use of both physiological and ethological approaches to assess the level of welfare of tigers kept in captivity. The purpose of this study was to assess the level of welfare of two Amur tigers (Panthera tigris altaica) housed at the Parco Natura Viva Zoological Park in Bussolengo (Verona, Italy) by analyzing both ethological and physiological parameters. In particular, when using the ethological method, both the individual and social behaviors of the animals were evaluated, while with the physiological approach, fecal cortisol metabolites were assessed.

\section{MATERIALS AND METHODS}

\section{Animals and Housing Conditions}

This study was performed between June 2012 and September 2012 at the Parco Natura Viva Zoological Park in Verona, Italy. The study was conducted on two Amur tigers: one male and one female. Both subjects were born in captivity. The 7 year old male that came from Vienna was parent-reared, whereas the 8-year old female that came from the Czech Republic was hand-reared. Furthermore, contraception was given to the female. In particular, two $10 \mathrm{mg}$ deslorelin (GnRH agonist) subcutaneous implants (Suprelorin $®$, Peptech Animal Health, Australia) were used. The contraceptive implant was applied on 31st December 2010. As noted by Munson, $10 \mathrm{mg}$ implants have proved to be effective for up to 2 years in cats housed in zoos (The American Zoo and Aquarium Contraception Advisory Group, AZA CAG, recommendations) (35). Both animals were fed with white and red meat six days a week, and one day of fasting was planned for both subjects every week. The tigers' enclosure consisted of an outdoor area exhibited to the public, and an off-view exhibit area divided into two separate enclosures each with an indoor and an outdoor area. Overnight, the cats were housed individually in the off-view area of the enclosure, whereas during daylight hours (from 8.30 a.m. to 6.30 p.m.), the tigers shared the outdoor area. The shared outdoor area $(2000 \mathrm{~m} 2)$ was characterized by lush vegetation, rocks, shelters and a pond. Animals were 
presented with different types of enrichment, such as physical and sensory enrichment both in the off-view exhibit area and in the outdoor area.

\section{Behavioral Recordings}

In order to assess animal welfare through ethological parameters, two daily 45-minute sessions were conducted for each individual; one in the morning (10.30 a.m. - 11.30 a.m.) and one in the afternoon (4.00 p.m. -5.30 pm). Twenty sessions per subject were run for a total of 900 minutes per individual. All observations were performed by the same researcher, in particular, one of the authors of this article. The Continuous Focal Animal Sampling method was used to record both individual and social behaviors overtime and the duration of each type of behavior (1). The ethogram of the behaviors recorded is reported in table 1. Furthermore, abnormal behaviors were recorded, in particular, pacing, which is a typical stereotypic behavior of captive big cats.

Table 1. Ethogram

\begin{tabular}{|c|c|}
\hline Behaviour & Definition \\
\hline \multicolumn{2}{|c|}{ Individual normal behaviour } \\
\hline Attention & The animal is motionless with its eyes open and alert to surroundings \\
\hline Exploration & $\begin{array}{l}\text { The animal explores the territory observing the environment, sniffing or } \\
\text { licking the ground, rocks, objects, sniffing the air, doing flehmen }\end{array}$ \\
\hline Individual play & $\begin{array}{l}\text { The animal manipulates or carries an object, plays running or jumping, rolls } \\
\text { on its back, swims, manifests predatory attitude }\end{array}$ \\
\hline Locomotion & Movement of the animal that resulted in a change of location \\
\hline Maintenance & $\begin{array}{l}\text { The animal shows behaviors aimed at physiological conservation (for } \\
\text { example: eat, drink, cough, shake the body, defecation or urination without } \\
\text { leaving signs) }\end{array}$ \\
\hline Self-grooming & $\begin{array}{l}\text { Licking / scratching one or more parts of its body, carding its hair, sharpening } \\
\text { its nails. The animal may be lying down, sitting or maintaining quadrupedal } \\
\text { station }\end{array}$ \\
\hline Territoriality & $\begin{array}{l}\text { The animal moves along the entire perimeter of the fence, yawns, marks the } \\
\text { territory by urinating / spraying, scratches vegetation }\end{array}$ \\
\hline \multicolumn{2}{|l|}{ Pathological behaviour } \\
\hline Pacing & $\begin{array}{l}\text { The animal walks the same straight/circular path repetitively with turning } \\
\text { points at the same location each time, repeating the action at least two times }\end{array}$ \\
\hline \multicolumn{2}{|l|}{ Social behaviour } \\
\hline Dominance & $\begin{array}{l}\text { The animal exhibits a dominant attitude roaring, showing teeth, raising the } \\
\text { tail, trying to hit the companion with or without contact }\end{array}$ \\
\hline Submission & $\begin{array}{l}\text { The animal shows an attitude of submission through actions such as: } \\
\text { lowering, lowering its head, showing the ventral side of the trunk, walking } \\
\text { away, taking a few steps backwards, avoiding / ignoring its companion, } \\
\text { looking away }\end{array}$ \\
\hline Interaction & $\begin{array}{l}\text { The animal interacts with companion sniffing, licking, or through attitudes that } \\
\text { do not clearly demonstrate dominance or submission (for example looking at } \\
\text { the conspecific) }\end{array}$ \\
\hline Attention towards visitors & $\begin{array}{l}\text { Interacts with visitors through observation } \\
\text { od approach to glass }\end{array}$ \\
\hline Attention to staff & $\begin{array}{l}\text { Interacts with staff showing a state of alert when it senses the noise of the } \\
\text { gator (service vehicle), moving when it perceives the sound of the gator, } \\
\text { observing staff }\end{array}$ \\
\hline \multicolumn{2}{|l|}{ Other } \\
\hline Out of sight & $\begin{array}{l}\text { Tiger is out of sight, or it is visible but not clearly enough to identify its } \\
\text { behavior }\end{array}$ \\
\hline
\end{tabular}




\section{Fecal Cortisol Analysis}

Over the study period, fecal samples were collected from both subjects: 5 samples from the male and 9 samples from the female. Fecal samples were generally collected in the morning, after releasing the animals into the exhibit area. However, when the male fecal samples were not found in the indoor area, the male was observed in order to locate the male feces, and then the male fecal sample was collected after the tigers returned to the off-view exhibit area in the late afternoon. Samples were collected in small plastic bags, sealed, and then stored in a $-20^{\circ} \mathrm{C}$ freezer before proceeding with analysis. The concentration of fecal cortisol and its metabolites was determined by enzyme immunoassay (EIA) using the commercial kit: Arbor Assays DetectX® Cortisol Enzyme Immunoassay Kit K003-H1W. The kit is designed to quantitatively measure the presence of cortisol in dried fecal extracts, saliva, urine, serum, plasma and tissue culture media samples. The kit has been developed for extracted fecal samples and has been validated with multiple animal species. Initially, the extraction procedure for steroid hormones, proposed by Schatz and Palme was used (48). Subsequently, hormonal dosage was carried out and the cortisol concentration of each sample was calculated using the 4PLC software.

\section{Statistical Analysis}

The data collected from this single-case research on the duration of each type of behavior was analyzed by using a nonparametric analysis $(16,52)$. The tests carried out using the Statview statistical software were: the Wilcoxon test, in order to compare the behaviors of each subject in the morning and in the afternoon and the Mann-Whitney test to underline the similarities and differences between the two tigers. In all tests, the level of statistical significance was set at $P<0.05$.

\section{RESULTS}

\section{Normal Behaviors}

The male showed significantly greater individual normal activity in the afternoon $(993.9 \pm 509.46 \mathrm{sec})$ than in the morning (161.2 $\pm 176.35 \mathrm{sec})$. (Wilcoxon test: $z=-2.666 ; \mathrm{P}=.0077)$ (Figure 1a). In particular, exploration (morning: $13.2 \pm 16.96$ sec; afternoon: $78.3 \pm 64.46 \mathrm{sec}$ ) (Wilcoxon test: $z=-2.310 ; P=.0209$ ), locomotion (morning: $101.8 \pm 112.3 \mathrm{sec}$; afternoon: $590.6 \pm 312.83 \mathrm{sec}$ ) (Wilcoxon test: $z=-2.666 ; P=.0077$ ), maintenance (morning: $2.3 \pm 7.27$ sec; afternoon: $26.1 \pm 19.47 \mathrm{sec}$ ) (Wilcoxon test: $\mathrm{z}=-2.366 ; \mathrm{P}=.0180$ ) and territoriality (morning: $43.9 \pm 53.11 \mathrm{sec}$; afternoon: $283.9 \pm 179.96 \mathrm{sec}$ ) (Wilcoxon test: $z=-2.666$; $P=.0077$ ) were performed significantly more in the afternoon than in the morning (Figure 2a). On the contrary, in general, the female did not perform significantly greater individual normal activity in the morning $(796.2 \pm 392.73 \mathrm{sec})$ than in the afternoon $(794.1 \pm 239.38 \mathrm{sec})$ (Wilcoxon test: $P>.05)($ Figure $1 \mathrm{~b})$. However, the female displayed significantly greater attention in the morning $(40.5 \pm 55.68 \mathrm{sec})$ than in the afternoon $(8.7 \pm$ $21.31 \mathrm{sec}$ ) (Wilcoxon test: $z=-2.371 ; P=.0177$ ) (Figure $1 \mathrm{~b}$ ) and spent a significantly greater proportion of her time exploring in the morning $(128.9 \pm 78.64 \mathrm{sec})$ than in the afternoon $(44.4 \pm 37.12 \mathrm{sec})$ (Wilcoxon test: $z=-1.988 ; P=.0469)$ (Figure 2b).

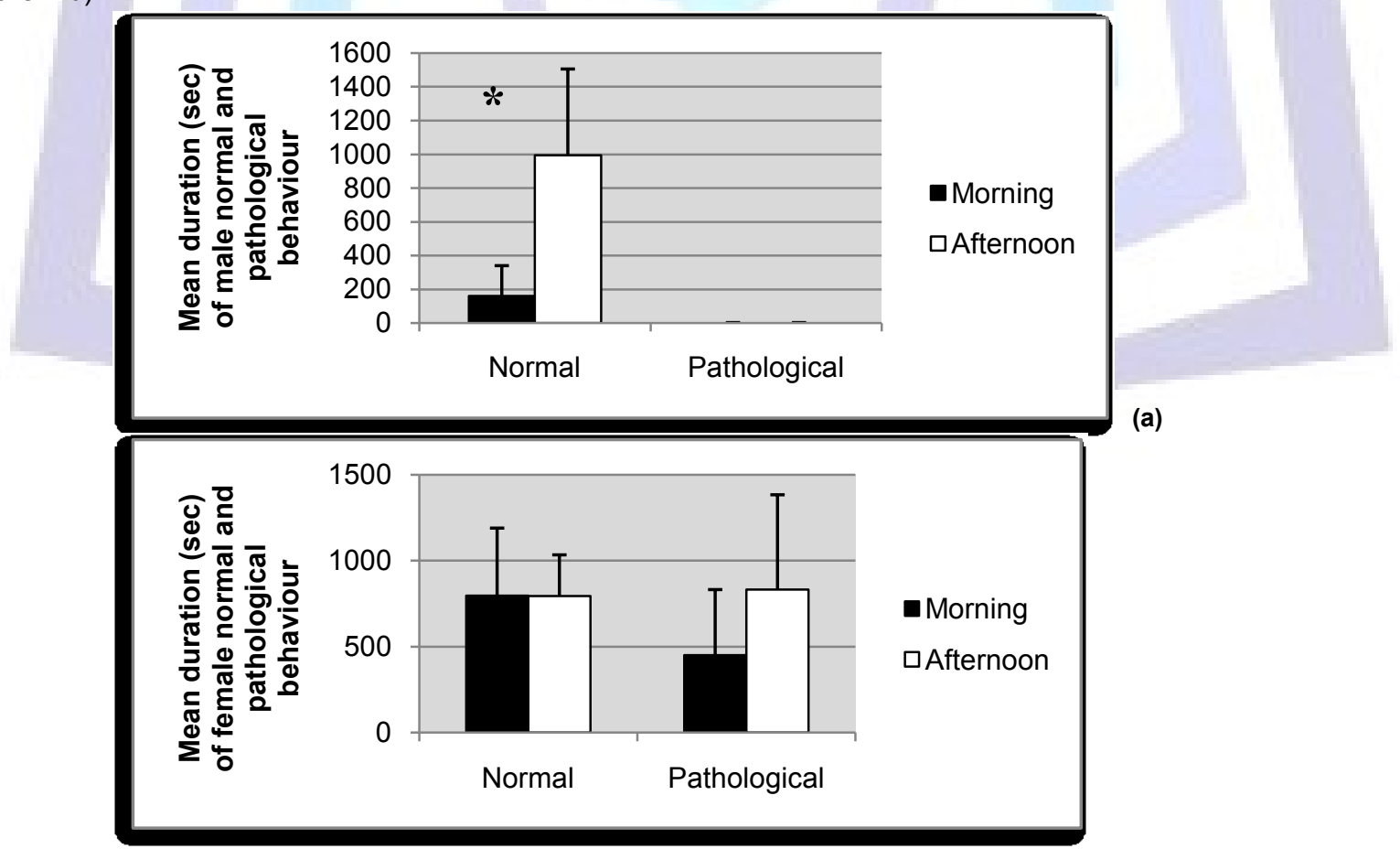

Figure 1. Mean duration, expressed in seconds, of individual normal beha(bior and individual pathological behavior manifested in the morning and in the afternoon by the male (a) and by the female (b). The error bars indicate the standard deviation. The asterisk indicates a significant difference in the expression of this behavior in the morning and in the afternoon at $P<.05$. 

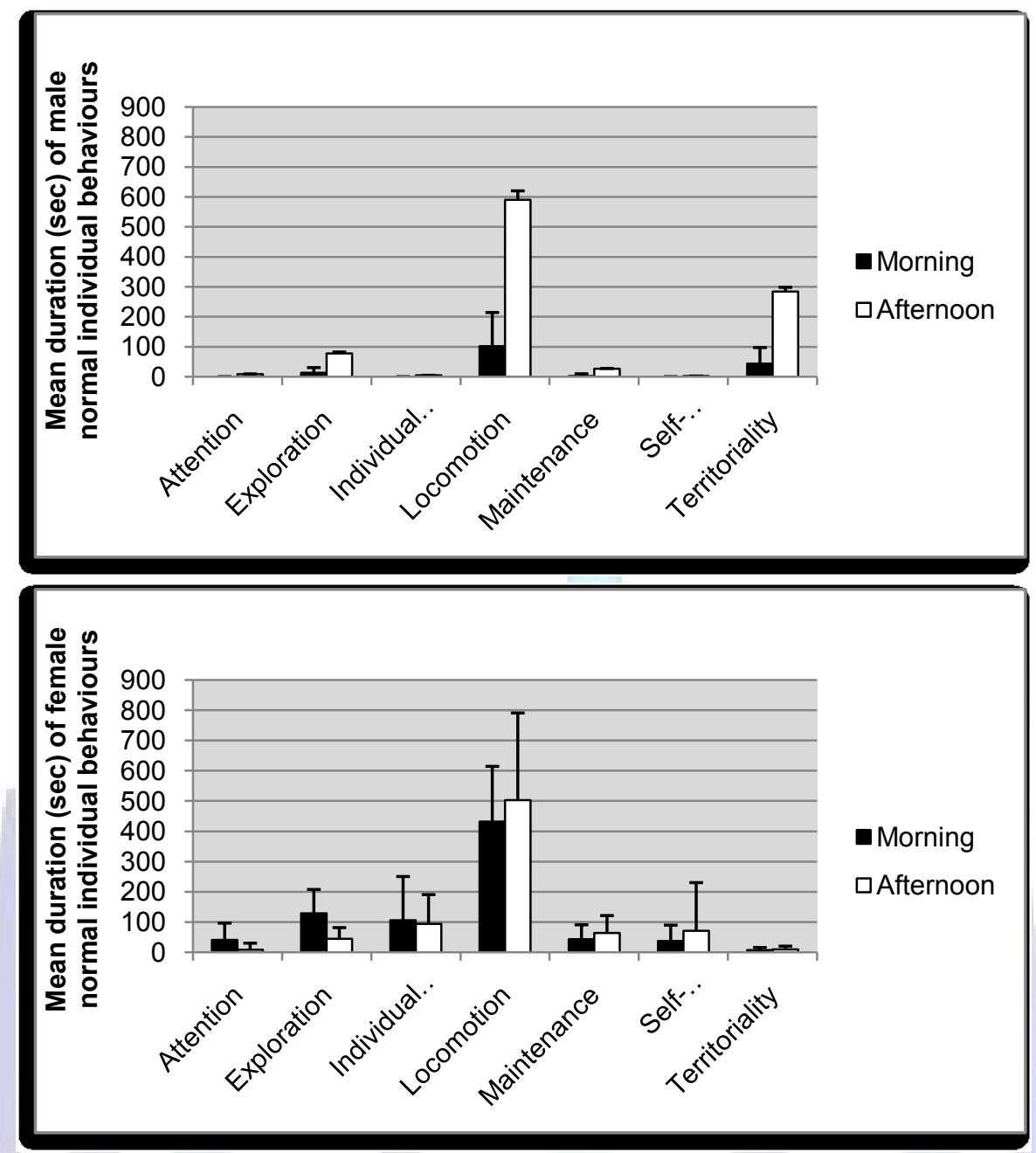

(a)

(b)

Figure 2. The mean duration, expressed in seconds, of each individual normal behavior exhibited in the morning and in the afternoon by the male (a) and by the female (b): attention, exploration,

individual play, locomotion, maintenance, self-grooming and territoriality. Error bars indicate the standard deviation. Asterisks indicate significant differences in the expression of that behavior in the morning and in the afternoon at $P<.05$.

Comparing the individual normal behaviors of the two animals, results highlight that in general, the female was significantly more active than the male in the morning (Mann-Whitney test: $U$ Prime $=95.000 ; P=.0006$ ). Indeed, during the morning, the female presented significantly greater attention and exploration than her companion did (Mann-Whitney test: $U$ Prime $=90.000 ; \mathrm{P}=.0006 ;$ Mann-Whitney test: $U$ Prime $=95.000 ; \mathrm{P}=.0006$, respectively). Furthermore, during the morning, the female expressed significantly more locomotion and maintenance than the male (Mann-Whitney test: U Prime $=91.000 ; P$ $=.0018$, Mann-Whitney test: U Prime $=82.500 ; \mathrm{P}=.0056$, respectively). In addition, the female showed significantly more individual play than the male, both in the morning (Mann-Whitney test: $U$ Prime $=80.000 ; \mathrm{P}=.0052$ ) and in the afternoon (Mann-Whitney test: $U$ Prime $=77.500 ; P=.0263$ ). Moreover, results show that self-grooming behavior was manifested significantly more by the female than the male both in the morning (Mann-Whitney test: $U$ Prime $=85.000 ; P=.0019$ ) and in the afternoon (Mann-Whitney test: $U$ Prime $=90.500 ; P=.0013$ ). Territoriality is the behavior which was performed significantly more by the male than the female in the afternoon (Mann-Whitney test: U Prime $=91.000 ; P=.0019$ ).

\section{Pathological Behaviors}

The female showed pathological behavior both in the morning $(450.7 \pm 380.78 \mathrm{sec})$ and in the afternoon $(831.1 \pm 551.7$ $\mathrm{sec}$ ) (Wilcoxon test: $\mathrm{P}>\mathrm{.05}$ ) (Figure $1 \mathrm{~b}$ ), whereas the male did not perform any pathological behaviors either in the morning (Mann-Whitney test: $U$ Prime $=90.000 ; \mathrm{P}=.0006$ ) or in the afternoon (Mann-Whitney test: $U$ Prime $=95.000 ; \mathrm{P}=$ .0002) (Figure 1a).

\section{Intraspecific Interaction}

In the case of the male, no significant differences in interaction ( $2.5 \pm 4.67 \mathrm{sec}, 36.8 \pm 74.87 \mathrm{sec}$ respectively) were found between morning and afternoon and neither in agonistic social behaviors (13.6 $\pm 36.52 \mathrm{sec}, 29.8 \pm 41.52 \mathrm{sec}$, respectively) (Wilcoxon test: $\mathrm{P}>\mathrm{.05}$ ) (Figure 3a). Whereas the female showed significantly more agonistic social behavior 
in the afternoon $(118.9 \pm 105.15 \mathrm{sec})$ than in the morning $(10.1 \pm 16.5 \mathrm{sec})$ (Wilcoxon test: $z=-2.521 ; P=.0117)($ Figure $3 b)$.

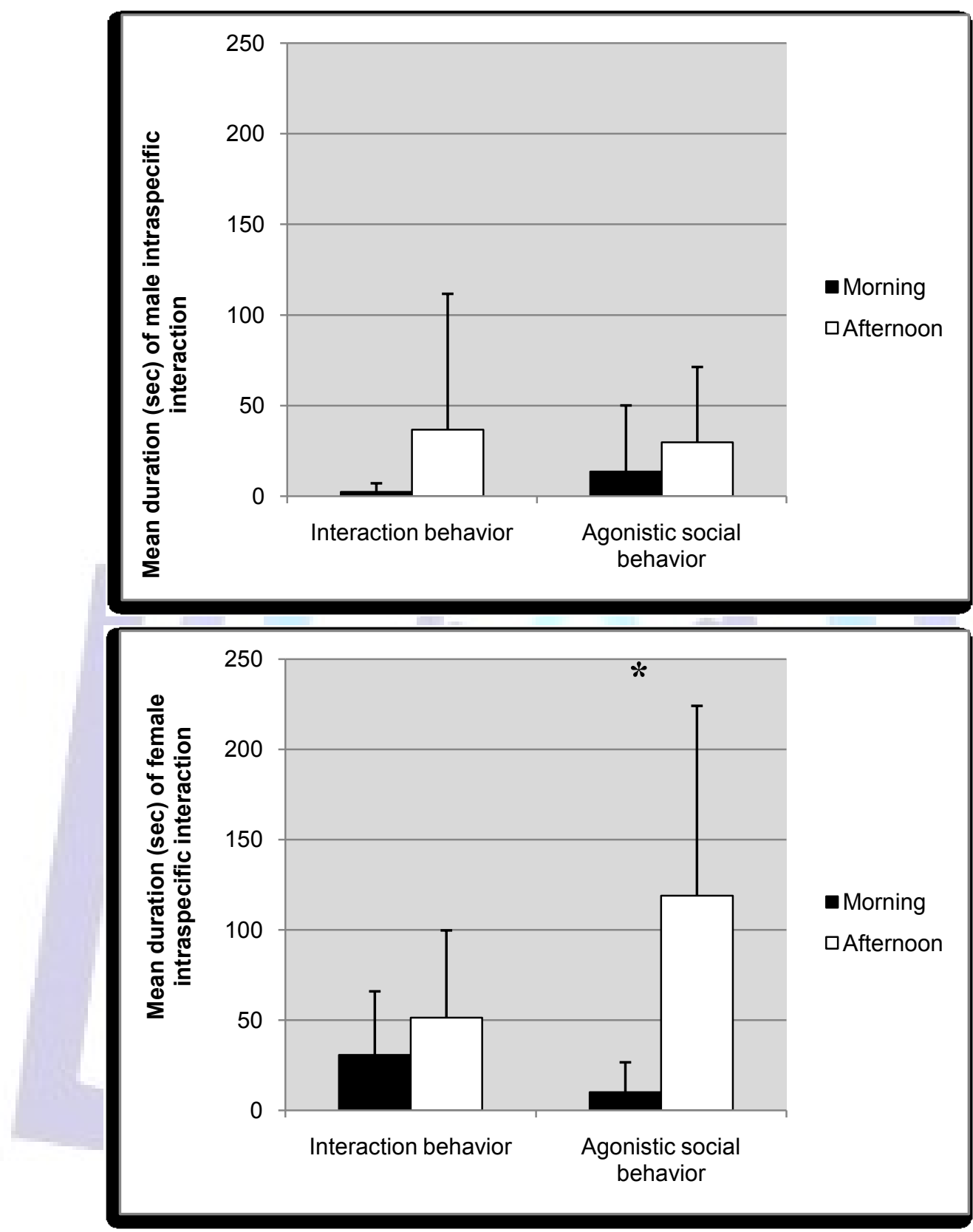

(a)

Figure 3. Mean duration, expressed in seconds, of interaction and agonistic social behavior manifested in the morning and in the afternoon by the male (a) and by the female (b). Error bars indicate the standard deviation. The asterisk indicates a significant difference in the expression of that behavior in the morning and in the afternoon at $P<.05$.

By comparing the social behaviors of the two tigers, results underline that during the morning the female showed significantly more interaction than her companion (Mann-Whitney test: $U$ Prime $=78.000 ; P=.0264$ ), whereas during the afternoon she performed significantly more agonistic social behavior than the male (Mann-Whitney test: $U$ Prime $=76.500$; $P=.0423$ ). Reproductive behavior was never observed due to fact that the female had a contraceptive implant.

\section{Interspecific Interaction}

Focusing on attention to visitors and to keepers, findings highlight that the male showed significantly greater attention to visitors in the afternoon $(45.5 \pm 33.22 \mathrm{sec})$ than in the morning $(3.8 \pm 5.35 \mathrm{sec})$ (Wilcoxon test: $\mathrm{z}=-2.668 ; \mathrm{P}=.0076)$ (Figure $4 a$ ), as well as to staff (afternoon: $11.1 \pm 14.8 \mathrm{sec}$ ) (morning: $0.3 \pm 0.95 \mathrm{sec}$ ) (Wilcoxon test: $z=-2.524 ; P=.0116$ ) (Figure $4 a)$. No significant differences were found between morning and afternoon in female interspecific interaction 
(Wilcoxon test: $P>$.05) (Figure 4b). Furthermore, in the morning, the female showed significantly more attention to visitors than the male (Mann-Whitney test: $U$ Prime $=96.000 ; P=.0004)$. In addition, the female showed significantly greater attention to staff than the male did both in the morning (Mann-Whitney test: $U$ Prime $=94.500 ; P=.0003$ ) and in the afternoon (Mann-Whitney test: $U$ Prime $=77.000 ; \mathrm{P}=.0408$ ).

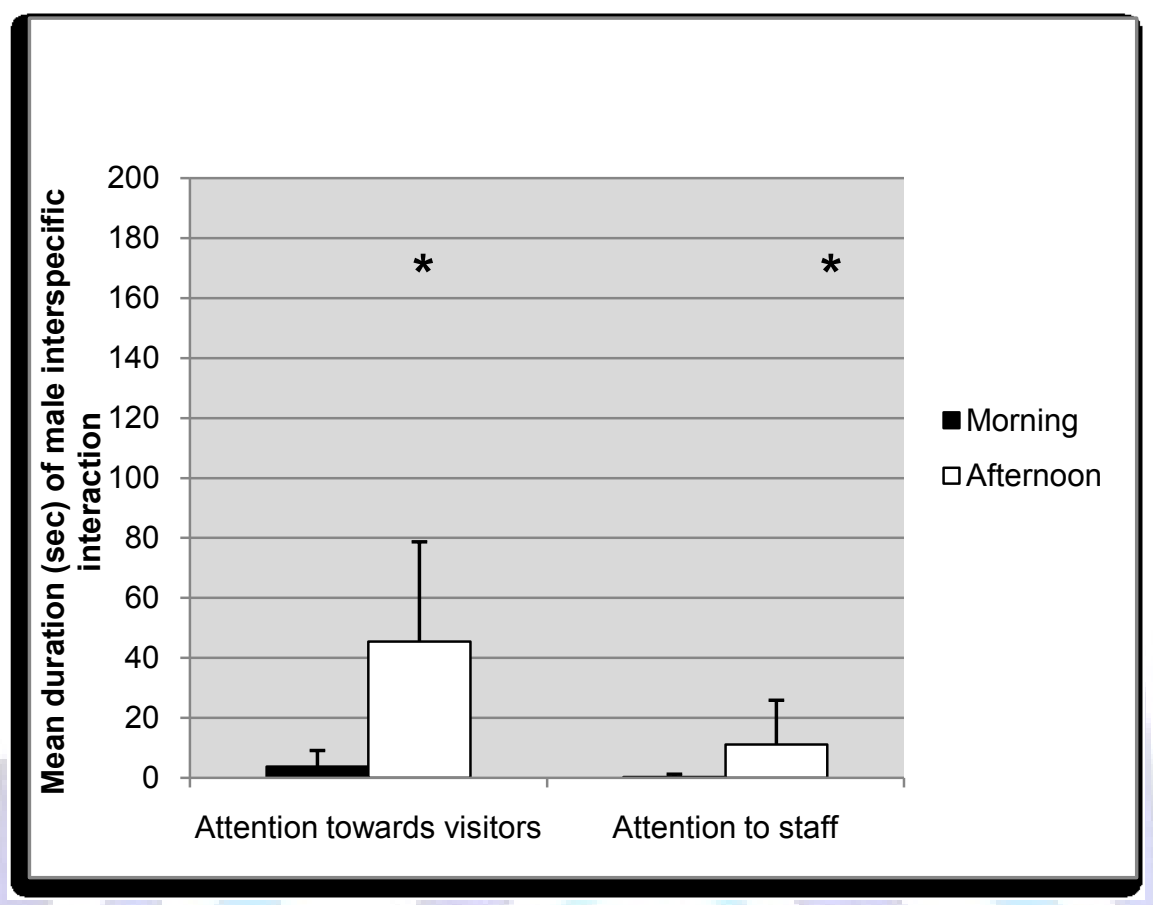

(a)

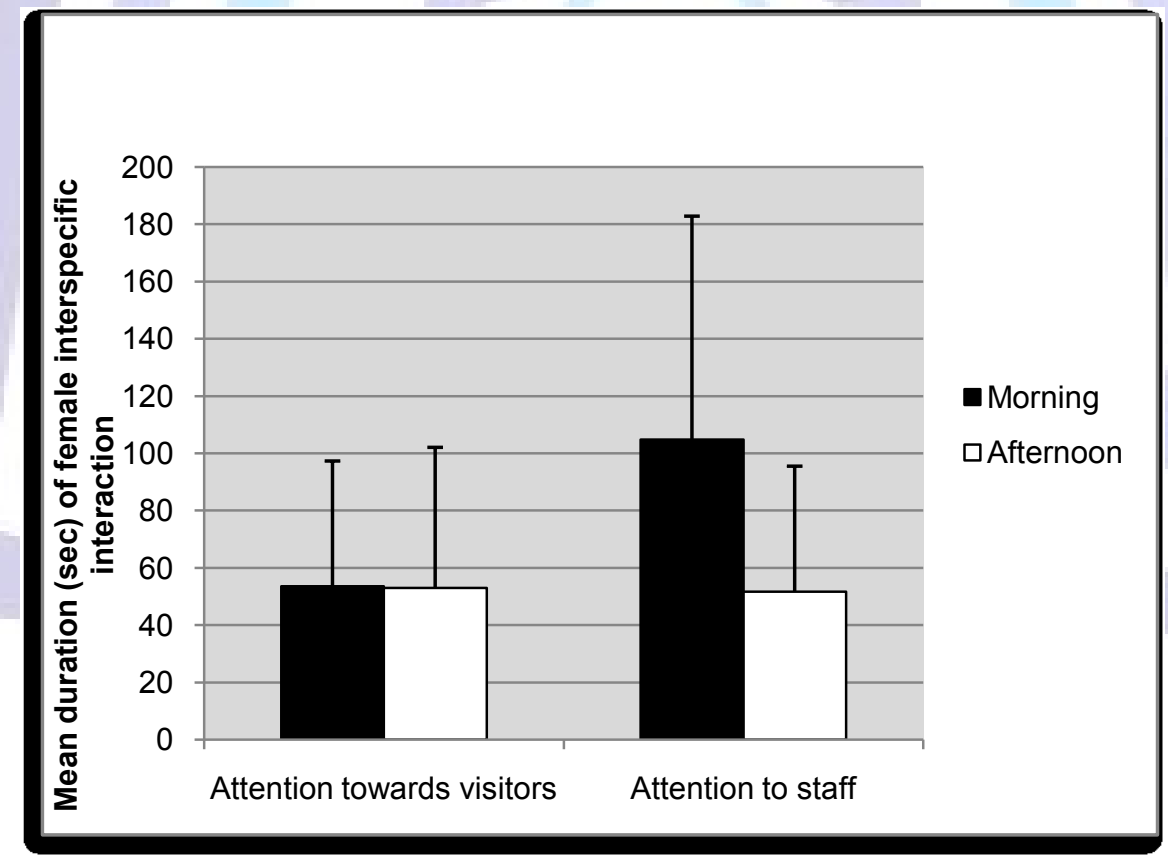

(b)

Figure 4. Mean duration, expressed in seconds, of attention towards visitors and attention to staff manifested in the morning and in the afternoon by the male (a) and by the female (b). Error bars indicate the standard deviation. Asterisks indicate significant differences in the expression of that behavior in the morning and in the afternoon at $P<.05$.

\section{Assessment of Fecal Cortisol Concentrations}

Regarding the male, the concentration of fecal cortisol was fairly constant, with values that did not exceed $19.56 \mathrm{ng} / \mathrm{g}$ feces (sample 4) (Figure 9a). The values recorded were: $10.59 \mathrm{ng} / \mathrm{g}$ feces (sample 3), $8.69 \mathrm{ng} / \mathrm{g}$ feces (sample 1), 7.12 $\mathrm{ng} / \mathrm{g}$ feces (sample 2) and $6.26 \mathrm{ng} / \mathrm{g}$ feces (sample 5) (Fig 5a). Considering the female, concentrations were quite variable; in particular, two peaks were recorded: $84.79 \mathrm{ng} / \mathrm{g}$ feces (sample 8) and $82.94 \mathrm{ng} / \mathrm{g}$ feces (sample 2). Afterwards, the concentrations detected were: $48.19 \mathrm{ng} / \mathrm{g}$ feces (sample 7), $44.89 \mathrm{ng} / \mathrm{g}$ feces (sample 6), $15.81 \mathrm{ng} / \mathrm{g}$ feces (sample 4), 
$10.14 \mathrm{ng} / \mathrm{g}$ feces (sample 5), $9.27 \mathrm{ng} / \mathrm{g}$ feces (sample 1), $8.47 \mathrm{ng} / \mathrm{g}$ feces (sample 3) and $8.11 \mathrm{ng} / \mathrm{g}$ feces (sample 9) (Figure $5 \mathrm{~b}$ ). Furthermore, the two animals were then compared. The median value for the male was lower than that obtained for the female, although no statistically significant difference was recorded (Mann-Whitney test: $P>.05)($ Table 2).
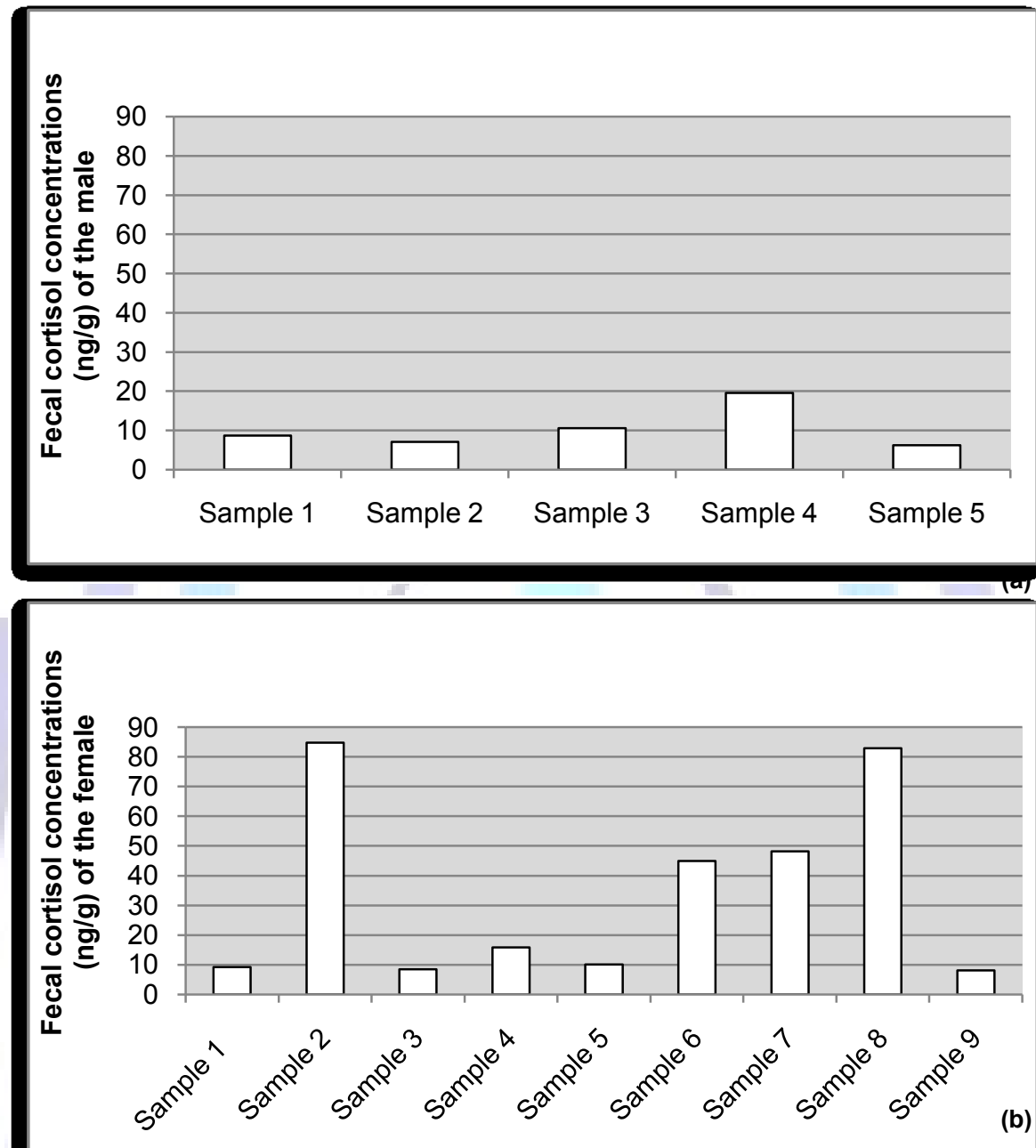

Figure 5. Fecal cortisol concentrations ( $\mathrm{ng} / \mathrm{g}$ ) recorded for the male (a) and for the female (b).

Table 2. Fecal cortisol concentrations (ng/g) for the male and for the female. Comparison between the two samples.

\begin{tabular}{|c|c|c|c|c|}
\hline \multicolumn{2}{|c|}{ Median (ng/g) } & \multicolumn{2}{c|}{ Range (ng/g) } & \multirow{2}{*}{$\begin{array}{c}\text { Mann-Whitney } \\
\text { test }\end{array}$} \\
\hline Male & Female & Male & Female & \multirow{P}{*}{$\mathbf{0 . 0 5}$} \\
\hline
\end{tabular}

\section{DISCUSSION}

In literature, there is a general consensus that the limitations of a captive environment can lead to the performance of stereotypic behavior $(29,53,57)$. Tigers are one of those species that can show problematic behavior in captivity (29). Moreover, the social environment and rearing technique might affect the normal behavior of the tiger (25, 31). Research is important to assess the welfare of these animals in order to adopt strategies to highlight species-specific behavior. Animal welfare can be assessed using both ethological and physiological parameters $(38,51)$. For most of the day, tigers are inactive or patrol their territory (65), whereas hunting takes place at night, even though some hunting can occur during the daytime (55). Furthermore, the tiger is an elusive species that makes it difficult to track how many of these animals exist in the wild (24). Furthermore, it may be difficult to see the tiger also in captivity when the enclosure permits the animal to 
express its elusive character. During the day, the tigers of this study, when visible, patrolled their territory and showed attentive behavior, which is essential for these animals (47). Most of the day, the male tiger in particular, was not visible showing elusiveness, a typical characteristic of this species. However, when subjects are hand-reared, the effect of rearing could change some species-specific behaviors. Indeed, during the day, the hand-reared female was more visible than the male, indicating that the presence of an audience may not be an element of disturbance (23). Both specimens also displayed more individual behavior and rarely took part in social activities. Indeed, the tiger is a solitary species, with the sole exception of coupling and the period in which the female takes care of her cubs (56). To remain on high alert relying primarily on sight and hearing is a species-specific behavior of tigers (47). Furthermore, exploration, locomotion, maintenance and territoriality are natural behaviors of big cats $(49,65)$. Both the male and female of this research performed all these behaviors and no significant differences were found between the two subjects. This result underlines the fact that the observed subjects showed the natural behaviors of big cats, even in captivity (65). However, while problematic behavior was not performed by the male, the female expressed abnormal behavior, in particular, pacing was observed. Pacing is one of the possible behavioral problems found in wild felines in zoos $(23,27)$. The self-grooming behavior is a species-specific behavior. However, when this behavior was performed more than other individual behaviors, the condition of the animals was considered as a possible bad condition $(3,63)$. The duration of self-grooming performed by the two tigers was less than all the other individual behaviors apart from territoriality highlighting a normal distribution of this behavior. Territoriality was manifested significantly more by the male than by the female, often by spraying urine and by rubbing his cheeks and chin on vegetation (49). This is a species-specific behavior manifested by males in order to defend and mark their territory to communicate to conspecifics the ownership of this (56). An important result of this study was the presence of individual play. This behavior is naturally shown by young animals and is usually not present in adults (49). However, the female of this study performed individual play more frequently than the male. Analyzing social activity, we distinguished intraspecific interaction and interaction with non-conspecific specimens, with particular reference to human beings. As regards intraspecific interaction, we found both affiliative and agonistic interactions typical of the species (49). The female showed intraspecific behaviors, in particular submissive behavior, especially in the afternoon when the male was more active. Another relevant result was that the female tiger repeatedly attempted to interact with her fellow involving him in gambling behavior showing a behavior typical of cubs even though the male did not respond to her behavior. The female, therefore, seems to not have developed the social skills necessary to establish regular interaction with a conspecific. This can be related to the fact that the animal was hand-reared, which can cause the inability of the adult to properly relate with conspecifics $(23,25,31)$. Interspecific social behavior, uncommon in nature, has great importance in a controlled environment and interspecific interaction varies greatly from subject to subject, being influenced by the experiences of each individual (23). The female tiger of this study showed a significantly higher interspecific interaction than the male due to the fact that the animal was hand-reared by human staff and not parent-reared. The handrearing strategy may alter the normal imprinting process of a subject, compromising his ability to relate well with other individuals be it with conspecifics or non-conspecifics (23). The findings of this study underline that the male seemed to have a good expression of the typical behaviors of the species, with distribution throughout the day concordant with what is reported in literature (65). Whereas, the female, alongside typical behaviors also performed atypical behaviors. Indeed, the female performed stereotypical pacing likely to be related to the weaning and hand-rearing of the subject resulting in altered social and individual behaviors (23). This was related to the strong presence of play and frequent submission performed by the female. Housing males and females together in captivity is reported to enrich the everyday life of the tiger (17). From our study it emerged that this may be true for the male, but not for the female. As regards the physiological approach to the assessment of animal welfare, it is widely recognized that the evaluation of the hormonal response and, in particular of the glucocorticoid response to stressful stimuli, is of fundamental importance $(9,40,64)$. The measurement of fecal cortisol can be useful to study animal welfare in the zoo environment assessing responses to stressors. Indeed, the excretion of metabolized blood steroids into the feces permits the monitoring of physiological functions without disturbance to animal subjects $(36,64)$. Moreover, given that the pooling of metabolites during excretion reduces the episodic secretion of blood glucocorticoids, it can be concluded that the analysis of fecal steroid metabolites gives a more representative measure of adrenocortical activity overtime (64). There are some limitations in the assessment of animal welfare through fecal cortisol levels. Indeed, there is a considerable inter-individual, as well as intraindividual variability (40). In animals, such as cats, dogs and chimpanzees, an important inter-individual variability has been found with significant differences in individual baseline fecal cortisol levels $(40,48,60)$. As regards intra-individual variability, some biological issues may affect fecal cortisol levels, for example, length of time in captivity, normal daily and seasonal variation in glucocorticoid excretion, reproductive status, sex, body condition or the animal's diet $(7,28,34,41$, $54,59,61,62)$. This makes comparing subjects difficult. It is therefore good practice to perform baseline measurements so that each individual may be considered as his own control $(39,40)$. In addition, evaluation of the current welfare state of an animal is made more difficult by the lack of reference values for wild and zoo animals. All the above leads to a greater difficulty in interpreting results (34). In this study, the analysis of fecal cortisol did not confirm the ethological results. Indeed, the female did not show significantly higher cortisol levels than the male. The appearance of behavioral changes, as well as the expression of pathological attitudes, did not necessarily correspond to a significant increase in the production of cortisol $(14,46)$. The evaluation of ethological parameters in assessing animal welfare may be considered a particularly sensitive method in order to detect a state of stress (2). However, a more accurate collection of samples in relation to the behavioral data collection is recommended for further studies.

\section{CONCLUSION}

In conclusion, the results of this study seem to confirm the importance of assessing the animal welfare of big cats since they may show abnormal behavior. Moreover, physiological and ethological parameters are necessary to underline the stressful condition of the animals. However, ethological parameters are more relevant and sensitive than physiological 
ones. Management of felines in captivity seems to be related to a main factor: the particular inclination of these animals to show abnormal behavior, such as stereotypical pacing behavior $(13,23,27)$, when hand-reared. The inability to properly relate with other individuals affects the process of being able to cope with the environment and with the subsequent negative effects on the well-being of the animal (23). This study may help zoo staff to identify a problematic situation of animal welfare and take action to improve the welfare of the subjects.

\section{REFERENCES}

[1] Altmann, J. (1974). Observational study of behavior: sampling methods. Behavior. 49, 227-267

[2] Arney, D. (2012). What is Animal Welfare and How is it Assessed? In C. Jakobsson (Ed.), Sustainable Agriculture - Ecosystem Health and Sustainable Agriculture Book 1 (pp. 311-315). Uppsala: The Baltic University Programme, Uppsala University. www.balticuniv.uu.se/index.php/component/docman/doc_download/1280chapter-42-what-is-animal-welfare-and-how-is-it-assessed-low-resolution

[3] Baker, R. (2006). Husbandry Guidelines For The Tiger Panthera tigris (Mammalia: Felidae). New South Wales $\begin{array}{lllll}\text { Fauna } \quad \text { Marine Association Inc. } & \end{array}$ http://nswfmpa.org/Husbandry\%20Manuals/Published\%20Manuals/Mammalia/Tiger.pdf

[4] Bashaw, M. J., Bloomsmith, M. A., Marr, M. J., and Maple, T.L. (2003). To hunt or not to hunt? A feeding enrichment experiment with captive lions and tigers. Zoo Biol. 22, 189-198.

[5] Bashaw, M. J., Kelling, A. S., Bloomsmith, M. A., and Maple, T. L. (2007). Environmental Effects on the Behavior of Zoo-housed Lions and Tigers, with a Case Study on the Effects of a Visual Barrier on Pacing. J. Appl. Anim. Welf. Sci. 10:2, 95-109, DOI: 10.1080/10888700701313116. http://dx.doi.org/10.1080/10888700701313116.

[6] Beck, B. B., and Power, M. L. (1988). Correlates of sexual and maternal competence in captive gorillas. Zoo Biol. 7, 339-350.

[7] Breuner, C. W., Wingfield, J. C., and Romero, L. M. (1999). Diel rhythms of basal nd stress-induced corticosterone in a wild, seasonal vertebrate, Gambel's white-crowned sparrow. J. Exp. Zool. 284, 334-342.

[8] Broom, D. M. (1986). Indicators of poor welfare. Brit. Vet J.142, 524-526.

[9] Broom, D. M. (1991). Animal welfare: concepts and measurement. J. Anim. Sci. 69, 4167-4175.

[10] Broom, D. M. (2001). The use of the concept of Animal Welfare in European conventions, regulations and directives. Food chain 2001 (pp. 148-151). Uppsala: SLU Services.

[11] Broom, D. M. (2007). Welfare in relation to feelings, stress and health. Revista Electrónica de Veterinaria, vol VIII No 12B. http://www.veterinaria.org/revistas/redvet/n121207B/BA018ing.pdf

[12] Broom, D. M., and Johnson, K. G. (1993). Stress and Animal Welfare. Dordrecht : Kluwer.

[13] Carlstead, K. (1996). Effects of captivity on the behavior of wild mammals. In D. G. Kleiman, M. E. Allen, K. V. Thompson, and S. Lumpkin (Eds.), Wild Mammals in Captivity (pp. 317-333). Chicago, IL: University of Chicago Press.

[14] Clark, F. E., Fitzpatrick, M., Hartley, A., King A.J., Lee, T., Routh, A., Walker, S. L., and George, K. (2012). Relationship between behavior, adrenal activity, and environment in zoo-housed western lowland gorillas (Gorilla gorilla gorilla). Zoo Biol. 31, 306-321, DOI: 10.1002/zoo.20396

[15] Clubb, R., and Mason, G. (2007). Natural behavioral biology as a risk factor in carnivore welfare: how analysing species differences could help zoos improve enclosures. Appl. Anim. Behav. Sci. 102, 303-328.

[16] Crawford, J. R., Garthwaite, P. H., Azzalini, A., Howell, D. C., and Laws, K. R. (2006). Testing for a deficit in single-case studies: Effects of departures from normality. Neuropsychologia. 44, 666-677.

[17] De Rouck, M., Kitchener, A. C., Law, G., and Nelissen, M. (2005). A comparative study of the influence of social housing conditions on the behavior of captive tigers (Panthera tigris). Anim. Welfare. 14, 229-238.

[18] Duffy, J. A., and Hendricks, S. E. (1973). Influences of social isolation during development on sexual behavior of the rat. Anim. Learn. Behav. 1, 223-227.

[19] Edwards, M. S., and Hawes, J. (1997). An overview of small felid hand-rearing techniques and a case study for Mexican margay Leopardus wiedii glaucula at the Zoological Society of San Diego. International Zoo Yearbook, $35,90-94$.

[20] Hakala, S., and Traylor-Holzer, K. (1994). Early maternal and cub behavior. In R. Tilson, G. Brady, K. TraylorHolzer, and D. Armstrong (Eds.), Management and conservation of captive tigers (pp. 73-75). Apple Valley, MN: Minnesota Zoo.

[21] Harlow, H. (1971). Learning to love. Chicago, IL: Aldine.

[22] Hogan, L. A., and Tribe, A. (2007). Prevalence and cause of stereotypic behavior in common wombats (Vombatus ursinus) residing in Australian zoos. Appl. Anim. Behav. Sci. 105, 180-191. 
[23] Hosey, G., Melfi, V., and Pankhurst, S. (2009). Zoo Animals Behavior, Management, and Welfare. Oxford: Oxford University Press.

[24] Karant, K. U., and Nichols, J. D. (2010). Non-invasive survey methods for assessing tiger populations. In R. Tilson, P. J. Nyhus (Eds.), Tigers of the world. The Science, Politics, and Conservation of Panthera Tigris, second ed. (pp. 241-261). London: Elsevier.

[25] Kelling, A. S., Bashaw, M. J., Bloomsmith, M. A., Terry, L., and Maple, T. L. (2013). Socialization of a Single Hand-Reared Tiger Cub. J. Appl. Anim. Welf. Sci. 16:1, 47-63, DOI: 10.1080/10888705.2013.741000 http://dx.doi.org/10.1080/10888705.2013.741000

[26] King, N. E., and Mellen, J. D. (1994). The effects of early experience on adult copulatory behavior in zoo-born chimpanzees Pan troglodytes. Zoo Biol. 13, 51-59.

[27] Lyons, J., Young, R. J., and Deag, J. M. (1997). The effects of physical characteristics of the environment and feeding regime on the behavior of captive felids. Zoo Biol. 16, 71-83.

[28] Marra, P. P., Lampe, K. T., and Tedford, B. L. (1995). Plasma corticosterone levels in two species of Zonotrichia sparrows under captive and free-living conditions. Wilson Bulletin, 107, 296-305.

[29] Mason, G., Clubb, R., Latham, N., and Vickery, S. (2007). Why and how should we use environmental enrichment to tackle stereotypic behavior? Appl. Anim. Behav. Sci. 102, 163-188.

[30] Meder, A. (1989). Effects of hand-rearing on the behavioral development of infant and juvenile gorillas Gorilla g. gorilla. Dev Psychol. 22, 357-376.

[31] Meier, J. E. (1986). Neonatology and hand-rearing of carnivores. In: M. E. Fowler (Ed.), Zoo and wild animal medicine, 2nd edition (pp. 842-852). Philadelphia, PA: W.B. Saunders.

[32] Mellen, J. D. (1992). Effects of early rearing experience on subsequent adult sexual behavior using domestic cats Felis catus as a model for exotic small felids. Zoo Biol. 11, 17-32.

[33] Mellen, J., and MacPhee, M. S. (2001). Philosophy of environmental enrichment: past, present, and future. Zoo Biol. 20, 211-226.

[34] Millspaugh, J. J., and Washburn, B. E. (2004). Use of fecal glucocorticoid metabolite measures in conservation biology research: considerations for application and interpretation. Gen. Comp. Endocr. 138:3, 189-199.

[35] Munson, L. (2006). Contraception in felids. Theriogenology. 66, 125-134, DOI:10.1016/j.theriogenology.2006.03.016

[36] Narayan, E. J., Parnell, T., Clark, G., Martin-Vegue, P., Mucci, A., and Hero, J. M. (2013). Fecal cortisol metabolites in Bengal (Panthera tigris tigris) and Sumatran tigers (Panthera tigris sumatrae). Gen. Comp. Endocr. 194, 318-325. http://dx.doi.org/10.1016/j.ygcen.2013.10.002

[37] Novak, M. A., and Sackett, G. P. (2006). The effects of rearing experience: The early years. In G. P. Sackett, G. C. Ruppentahal, and K. Elias (Eds.), Nursery rearing of nonhuman primates in the 21st century (pp. 3-19). New York, NY: Springer Science C Business Media.

[38] Palme, R. (2012). Monitoring stress hormone metabolites as a useful, non-invasive tool for welfare assessment in farm animals. Anim. Welfare. 21, 331-337. DOI: 10.7120/09627286.21.3.331

[39] Palme, R., Robia, C., Messmann, S., Hofer, J., and Möstl, E. (1999). Measurements of fecal cortisol metabolites in ruminants: a non-invasive parameter of adrenal function. Wien. Tierarztl. Monat. 86, 237-241.

[40] Queyras, A., and Carosi, M. (2004). Non-invasive techniques for analysing hormonal indicators of stress. Ann. Ist. Super. Sanità. 40:2, 211-221.

[41] Raminelli, J. L. F., de Sousa, M. B. C., Cunha, M. S., and Barbosa, M. F. V. (2001). Morning and afternoon patters of fecal cortisol excretion among reproductive and non-reproductive male and female common marmosets, Callithrix jacchus. Biol. Rhythm. Res. 32, 159-167.

[42] Read, B. W., and Meier, J. E. (1996). Neonatal care protocols. In D. G. Kleiman, M. E. Allen, K. V. Thompson, and S. Lumpkin (Eds.), Wild mammals in captivity: Principles and techniques (pp. 41-55). Chicago, IL: University of Chicago.

[43] Richardson, D. M. (1988). Hand-rearing exotic felids. In R. Colley (Ed.), The hand-rearing of wild animals (pp. 51-54). Bristol, UK: Association of British Wild Animal Keepers.

[44] Richardson, D. M. (1991). Guidelines for handrearing exotic felids. In J. Partridge (Ed.), Management guidelines for exotic cats (pp. 116-117). Bristol, UK: Association of British Wild Animal Keepers.

[45] Ryan, S., Thompson, S. D., Roth, A. M., and Gold, K. C. (2002). Effects of hand-rearing on the reproductive success of western lowland gorillas in North America. Zoo Biol. 21, 389-401.

[46] Sajjad, S., Farooq, U., Anwar, M., Khurshid, A., and Bukhari, S. A. (2011). Effect of captive environment on plasma cortisol level and behavioral pattern of Bengal tigers (Panthera tigris tigris). Pak. Vet. J. 31:3, 195-198. 


\section{ISSN 2349-0837}

[47] Schaller, G. B. (1967). The Deer and the Tiger. Chicago: University of Chicago Press.

[48] Schatz, S., and Palme, R. (2001). Measurement of fecal cortisol metabolites in cats and dogs: a non-invasive method for evaluating adrenocortical function. Vet. Res. Commun. 25, 271-287.

[49] Seidensticker, J., and Lumpkin, S. (1992). Tigri, Leoni e Altri Felini. Milano: Rizzoli.

[50] Selye, H. (1973). The evolution of the stress concept. Am. Sci. 61, 692-699.

[51] Shepherdson, D. J., Carlstead, K. C., and Wielebnowski, N. (2004). Cross-institutional assessment of stress responses in zoo animals using longitudinal monitoring of fecal corticoids and behavior. Anim. Welfare. 13:S1, 105-113.

[52] Sheskin, D. J. (2011). Handbook of Parametric and NonParametric Statistical Procedures, 5th Revised edition. Boca Raton, FL: Chapman and Hall/CRC Press.

[53] Shyne, A. (2006). Meta-analytic review of the effects of enrich-ment on stereotypic behavior in zoo mammals. Zoo Biol. 25, 317-337.

[54] Smith, G. T., Wingfield, J. C., and Veit, R. R. (1994). Adrenocortical response to stress in the common diving petrel, Pelecanoides urinatrix. Physiol. Zool. 67, 526-537.

[55] Sunquist, M. (2010). What is a tiger? Ecology and behavior. In: R. Tilson, and P. J. Nyhus (Eds.), Tigers of the world. The Science, Politics, and Conservation of Panthera tigris, second ed. (pp. 19-33). London: Elsevier.

[56] Sunquist, M. E., and Sunquist, F. C. (2002). Wild Cats of the World. Chicago: The University of Chicago Press.

[57] Swaisgood, R. R., and Shepherdson, D. J. (2005). Scientific approaches to enrichment and stereotypies in zoo animals: what's been done and where should we go next? Zoo Biol. 24, 499-518.

[58] Szokalski, M. S., Litchfield, C. A., and Foster, W. K. (2012). Enrichment for captive tigers (Panthera Tigris): Current knowledge and future directions. App. Anim. Behav. Sci. 139, 1-9.

[59] Touma, C., Sachser, N., Möstl, E., and Palme, R. (2003). Effects of sex and time of day on metabolism and excretion of corticosterone in urine and feces of mice. Gen. Comp. Endocrinol. 130, 267-278.

[60] Whitten, P. L., Stavisky, R., Aureli, F., and Russell, E. (1998). Response of fecal cortisol to stress in captive chimpanzees (Pan troglodytes). Am. J. Primatol. 44:1, 57-69.

[61] Whittier, J. M., Corrie, F., and Limpus, C. (1997). Plasma steroid profiles in nesting loggerhead turtles (Caretta caretta) in Queensland, Australia: relationship to nesting episode and season. Gen. Comp. Endocrinol. 106, 3947.

[62] Wingfield, J. C., Suydam, R., and Hunt, K. (1994). The adrenocortical responses in snow buntings (Plectrophenax nivalis) and Lapland longspurs (Calcarius lapponicus) at Barrow, Alaska. Comp. Biochem. Phys. C. $108,299-306$.

[63] Wooster, D. S. (1997). Enrichment technique for small felids at Woodland Park Zoo, Seattle. International Zoo Yearbook, 35, 208-212.

[64] Young, K. M., Walker, S. L., Lanthier, C., Waddell, W. T., Monfort, S. L., and Browna, J. L. (2004). Noninvasive monitoring of adrenocortical activity in carnivores by fecal glucocorticoid analyses. Gen. Comp. Endocrinol. 137, 148-165.

[65] Zhen-sheng, L., Feng, L., Li-wei, T., and Xiao-yu, Z. (2002). Time budget of semifree-ranging Amur Tigers (Panthera tigris altaica). Zool. Res. 5, 389-439. 